\title{
Noninvasive Quantification of Hepatic Steatosis: Relationship Between Obesity Status and Liver Fat Content
}

\author{
S. C. McLeay ${ }^{1,2}$, G. A. Morrish ${ }^{2}$, T. K. Ponnuswamy ${ }^{3}$, B. Devanand ${ }^{3}$, M. Ramanathan ${ }^{4}$, \\ L. Venkatakrishnan ${ }^{3}$, S. Ramalingam ${ }^{3}$ and B. Green ${ }^{2, *}$ \\ ${ }^{I}$ School of Pharmacy, The University of Queensland, Brisbane, Queensland, Australia \\ ${ }^{2}$ Model Answers Pty Ltd, Brisbane, Queensland, Australia \\ ${ }^{3}$ PSG Institute of Medical Sciences and Research, Coimbatore, India \\ ${ }^{4}$ PSG College of Pharmacy, Coimbatore, India
}

\begin{abstract}
The aim of this study was to assess and compare fat content within the liver for normal (body mass index (BMI) $\left.<25 \mathrm{~kg} / \mathrm{m}^{2}\right)$, overweight $\left(25-30 \mathrm{~kg} / \mathrm{m}^{2}\right)$ and obese $\left(\geq 30 \mathrm{~kg} / \mathrm{m}^{2}\right)$ subjects using a noninvasive, non-contrast computed tomography (CT) quantification method. Adult subjects aged 18-60 yrs scheduled to undergo CT examination of the abdominal region were recruited for this study, stratified across BMI categories. Liver volume, fat content, and lean liver volume were determined using CT methods. A total of 100 subjects were recruited, including 30 normal weight, 31 overweight, and 39 obese. Total liver volume increased with BMI, with mean values of $1138 \pm 277,1374 \pm 331$, and 1766 $\pm 389 \mathrm{~cm}^{3}$ for the normal, overweight, and obese, respectively $(P<0.001)$, which was due to an increase in both liver fat content and lean liver volume with BMI. Some obese subjects had no or minimal hepatic fat content. The prevalence of mild fatty liver in this study of 100 subjects was overestimated for all BMI categories using a range of qualitative diagnostic measures, with predicted prevalence of fatty liver in obese subjects ranging from $76.9 \%$ for liver-to-spleen ratio $\leq 1.1$ to $89.7 \%$ for liver attenuation index (liver $\mathrm{HU}$ - spleen $\mathrm{HU}$ ) $\leq 40$, compared to $66.7 \%$ by quantification of fat content. Results show that total liver volume increases with BMI, however, not all obese subjects display fatty infiltration of the liver. CT quantification of liver fat content may be suitable for accurate diagnosis of hepatic steatosis in clinical practice and assessment of donor livers for transplantation.
\end{abstract}

Keywords: Body mass index, computed tomography, fatty liver, hepatic steatosis, obesity.

\section{INTRODUCTION}

Fatty infiltration of the liver, or hepatic steatosis, is a common condition reported to affect up to $30 \%$ of the general Western population [1]. It is associated with obesity $[2,3]$ and can lead to irreversible liver damage associated with inflammation, termed nonalcoholic steatohepatitis (NASH). Left undiagnosed, NASH can further progress to cirrhosis and fibrosis, resulting in an increased risk of cardiovascular disease, type 2 diabetes mellitus, and hepatocellular carcinoma [4]. Hepatic steatosis can also influence the outcome of liver transplantation [5-7] with livers from obese donors or those with extensive steatosis resulting in an increased incidence of ischemic injury and primary nonfunction [8]. It is important, therefore, that fat content of livers can be accurately assessed to ensure the best outcomes for patients, although it is well accepted that a liver biopsy is the only method that can distinguish between benign steatosis and active NASH. Unfortunately, no

*Address correspondence to this author at the Model Answers Pty Ltd, Level 5, 99 Creek St, Brisbane, Qld, Australia, 4000; Tel: +61 73221 1315; Email: modelanswers@gmail.com imaging technique can replace a biopsy to confirm NASH. Furthermore, with the increasing worldwide prevalence of obesity [9], understanding liver fat content in the overweight and obese is of increased significance.

Although liver biopsy is considered to be the most practical and objective method to quantify fat content [10], it is not suitable as a primary method of screening due to its invasiveness, risk of complications, and associated costs [11-13]. As such, ultrasound, computed tomography (CT), and magnetic resonance imaging (MRI) have been investigated as noninvasive methods for diagnosing fatty liver $[14,15]$. Of these three imaging methods, CT is most commonly used because of its increased accuracy and objectivity compared to ultrasound [15], and lower costs compared to MRI $[16,17]$.

Non-contrast CT attenuation of the liver (in Hounsfeld units, HU) correlates well with pathological fat content $[14,18]$, with a number of methods proposed to identify hepatic steatosis using CT. These include absolute hepatic attenuation value, liver-to-spleen ratio (L/S), and liver attenuation minus splenic attenuation ('liver attenuation index', LAI) [17]. However, these methods only provide a 
qualitative assessment of steatosis based upon a range of arbitrary cutoffs reported in the literature, e.g. liver attenuation $\leq 40 \mathrm{HU}[19], \mathrm{L} / \mathrm{S} \leq 1.1$ [17], LAI $\leq 5$ [17, 20], and cannot be used to accurately quantify the extent of fatty infiltration. As such, Ricci et al. [18] developed a CT calibration method using reference objects that allows fat content to be derived from hepatic attenuation values. Although this method facilitates accurate assessment of hepatic fat content [18], calibration of the CT machine is performed for each subject, making the method impractical for regular clinical use.

The aim of this study was to assess and compare liver fat content for subjects within normal, overweight and obese BMI categories using a noninvasive non-contrast CT quantification method. Additionally, we aimed to assess the intra- and inter-day accuracy and precision of CT machine calibration using reference objects that simulate various hepatic fat contents and determine whether calibration is required for each subject.

\section{PATIENTS AND METHODS}

\section{Subjects}

Adult Indian (Caucasian) medical patients aged 18-60 yrs scheduled to undergo a CT scan of the abdomen or neighboring anatomical region were recruited from PSG Hospital, Coimbatore, India. All subjects underwent ultrasonography screening of the liver prior to recruitment and were excluded if there was evidence of hepatic structural abnormality. Subjects were also excluded if they had abnormal liver or kidney function tests (determined as values outside normal reference ranges), were undergoing current treatment for a medical condition related to the liver or kidney, were pregnant, or were breastfeeding.

Subjects were stratified into 3 groups of approximately equal size according to body mass index (BMI): normal weight $\left(<25 \mathrm{~kg} / \mathrm{m}^{2}\right)$, overweight $\left(25-30 \mathrm{~kg} / \mathrm{m}^{2}\right)$, and obese $\left(\geq 30 \mathrm{~kg} / \mathrm{m}^{2}\right)$. Assuming equal recruitment of subjects into each BMI category $(n=33)$, this study design would be sufficient to determine with $80 \%$ power a moderate to large difference between groups at an alpha level of 0.05 [21].

Ethics approval for this study was obtained from the Medical Research Ethics Committee, The University of Queensland, Brisbane, Australia and the Institutional Human Ethics Committee, PSG Institute of Medical Sciences \& Research, Coimbatore, India. All subjects gave informed consent prior to participation in the study.

\section{Calculation of Body Composition}

Lean body weight (LBW) for each subject was estimated using the equations by Janmahasatian et al. [22]:

$$
\begin{aligned}
& \mathrm{LBW}(\text { males })=(9270 \times \mathrm{WT}) /(6680+216 \times \mathrm{BMI}) \\
& \mathrm{LBW}(\text { females })=(9270 \times \mathrm{WT}) /(8780+244 \times \mathrm{BMI})
\end{aligned}
$$

where WT is total body weight in $\mathrm{kg}$. Body fat was calculated as WT minus LBW and expressed as a percentage of WT, i.e.:

Body fat $(\%)=(\mathrm{WT}-\mathrm{LBW}) / \mathrm{WT} \times 100$

\section{CT Machine}

CT evaluation was performed with a Siemens SOMATOM Sensation 64 scanner using $120 \mathrm{Kvp}, 125 \mathrm{mAs}$ and slice collimation of $0.6 \mathrm{~mm}$ (acquisition: 64 slices $\mathrm{x} 0.6$ $\mathrm{mm})$ with a scan time of $9.6 \mathrm{sec}$.

\section{CT Calibration}

Reference objects were created to mimic different degrees of fat content according to the method by Ricci et al. [18]. Terbutyl alcohol, which has been shown to display a similar CT scan density to fat tissue [18], was added in increasing concentrations of $0,10,20,30 \& 40 \%$ to an $18.5 \%(\mathrm{w} / \mathrm{v})$ glucose solution and sealed in Perspex tubes (fabricated by the PSG Engineering Department, length $10 \mathrm{~cm}$, inner diameter $1.5 \mathrm{~cm}$, outer diameter $2.5 \mathrm{~cm}$ ). As an $18.5 \%(w / v)$ glucose solution demonstrates the same CT scan density (55 Hounsfeld units, HU) as normal fat-free liver $(55 \pm 2 \mathrm{HU})$ [18], the tubes therefore simulated increasing liver fat contents of $0,10,20,30 \& 40 \%$, respectively. Sodium azide $(0.02 \%)$ was added to the solution to prevent microbial growth.

The intra-day variability in CT HU readings was evaluated by 10 repeat measurements of each of the reference objects, and the inter-day variability was assessed over 6 separate days across a two-week period. Accuracy was assessed as a percentage of the actual fat content (accuracy $(\%)=$ measured fat content/actual fat content $\mathrm{x}$ $100)$, and precision was determined as the coefficient of variation $(\% \mathrm{CV}=$ standard deviation/mean $\mathrm{x} 100)$. The calibration curve was developed by least squares linear regression of the non-weighted inter-day HU readings of the 5 reference objects.

\section{CT Measurement}

For each subject, attenuation readings were taken from each of the following four locations within the liver: (a) the dome of the liver, (b) cephalic to the hepatic hilum, (c) caudal to the hepatic hilum, and (d) immediate to the inferior margin of the right lobe. Four replicate readings were taken from each region of interest to ensure consistency, and care was taken to sample homogeneous areas devoid of vessels, bile ducts and focal lesions. Attenuation readings were compared between locations within the liver, and the mean reading was used to determine hepatic fat content using the equation developed from the calibration curve. Lean liver volume was determined as total liver volume minus fat volume (where fat volume $=$ fat content (\%) $\mathrm{x}$ total liver volume). The mean of two readings from the spleen was used for determination of the liver-tospleen ratio (liver HU/spleen HU, L/S) and liver attenuation index (LAI) (liver HU minus spleen HU).

Liver volume was determined from $91 \mathrm{CT}$ slices using the Syngo ${ }^{\circledR}$ Suite software package (version VB 20B).

\section{Statistical Analysis}

Statistical analysis of data was performed using $\mathrm{R}$ version 2.13.0 (C) 2004-2011 The R Foundation for Statistical Computing, http://www.R-project.org). Data including liver volume, WT-normalized liver volume (i.e. liver volume divided by WT), percent liver fat, liver 
Table 1. Subject demographics. Values are presented as mean \pm standard deviation (range). P-values calculated using Pearson's chisquared test (categorical data), ANOVA or Shapiro-Willk test (continuous data). NS, not significant.

\begin{tabular}{|c|c|c|c|c|c|}
\hline & $\begin{array}{c}\text { Normal } \\
\begin{array}{c}\left(\mathrm{BMI}<25 \mathrm{~kg} / \mathrm{m}^{2}\right) \\
n=30\end{array}\end{array}$ & $\begin{array}{c}\text { Overweight } \\
\text { (BMI 25-30 kg/m²) } \\
n=31\end{array}$ & $\begin{array}{c}\text { Obese } \\
\left(\mathrm{BMI} \geq \mathbf{3 0} \mathrm{kg} / \mathrm{m}^{2}\right) \\
n=39\end{array}$ & $\begin{array}{l}\text { All Subjects } \\
\quad n=100\end{array}$ & P-value \\
\hline Sex (male, female) & $24 \mathrm{~m}, 6 \mathrm{f}$ & $21 \mathrm{~m}, 10 \mathrm{f}$ & $25 \mathrm{~m}, 14 \mathrm{f}$ & $70 \mathrm{~m}, 30 \mathrm{f}$ & NS \\
\hline Age (yrs) & $\begin{array}{c}34.0 \pm 9.3 \\
(18-57)\end{array}$ & $\begin{array}{c}41.0 \pm 10.6 \\
(24-66)\end{array}$ & $\begin{array}{c}40.3 \pm 7.0 \\
(25-60)\end{array}$ & $\begin{array}{c}38.6 \pm 9.3 \\
(18-66)\end{array}$ & $<0.01$ \\
\hline Weight (kg) & $\begin{array}{c}58.5 \pm 8.1 \\
(45-74)\end{array}$ & $\begin{array}{c}74.7 \pm 10.0 \\
(54-91)\end{array}$ & $\begin{array}{c}92.7 \pm 11.9 \\
(70-128)\end{array}$ & $\begin{array}{c}76.8 \pm 17.5 \\
(45-128)\end{array}$ & $<0.001$ \\
\hline Height $(\mathrm{cm})$ & $\begin{array}{c}164 \pm 10.3 \\
(148-197)\end{array}$ & $\begin{array}{c}164 \pm 10.0 \\
(143-189)\end{array}$ & $\begin{array}{l}163 \pm 8.1 \\
(146-177)\end{array}$ & $\begin{array}{r}164 \pm 9.3 \\
(143-197)\end{array}$ & NS \\
\hline $\operatorname{BMI}\left(\mathrm{kg} / \mathrm{m}^{2}\right)$ & $\begin{array}{c}21.7 \pm 2.3 \\
(16.9-24.7)\end{array}$ & $\begin{array}{c}27.7 \pm 1.6 \\
(25.2-29.8)\end{array}$ & $\begin{array}{c}34.8 \pm 4.3 \\
(30.1-51.8)\end{array}$ & $\begin{array}{c}28.7 \pm 6.2 \\
(16.9-51.8)\end{array}$ & $<0.001$ \\
\hline Lean body weight (kg) & $\begin{array}{c}46.0 \pm 8.0 \\
(30.8-63.5)\end{array}$ & $\begin{array}{l}51.7 \pm 10.1 \\
(32.9-68.8)\end{array}$ & $\begin{array}{c}56.8 \pm 9.1 \\
(38.7-75.5)\end{array}$ & $\begin{array}{l}52.0 \pm 10.1 \\
(30.8-75.5)\end{array}$ & $<0.001$ \\
\hline Body fat $(\%)$ & $21.5 \pm 7.2(10.3-37.0)$ & $31.1 \pm 6.8(23.5-42.2)$ & $\begin{array}{c}38.6 \pm 7.3 \\
(29.7-52.4)\end{array}$ & $\begin{array}{l}31.1 \pm 10.0 \\
(10.3-52.4)\end{array}$ & $<0.001$ \\
\hline
\end{tabular}

attenuation, L/S, LAI, and liver fat-to-body fat ratio were plotted as functions of BMI category and described as mean \pm standard deviation (SD). Liver fat-to-body fat ratio was also examined as a function of age, with age categories of $<30,30-40,40-50$, and >50yrs.

Pearson's chi-squared test was used for statistical comparison of categorical data. The distributions of continuous data were determined using the normal Shapiro-Wilk normality test. For normally-distributed data, ANOVA and Tukey's honestly significant differences were used for statistical comparison of groups, and for non-normal data, Kruskal-Wallis rank sum and multiple comparisons tests were used. A P-value $<0.05$ was considered to be statistically significant.

The prevalence of mild fatty liver, which was considered to be measured fat content $\geq 5 \%$ as defined by Sherlock et al. [23] and Kleiner et al. [24], was compared to the prevalence of fatty liver determined according to a variety of qualitative diagnostic methods. These included absolute liver attenuation $\leq 40 \mathrm{HU}[19], \mathrm{L} / \mathrm{S} \leq 1.1[17]$, and $\mathrm{LAI} \leq 5[17,20]$.

\section{RESULTS}

\section{Subjects}

A total of 100 subjects were recruited for the study. Demographics are shown in Table 1. There were no significant differences between male/female ratio in each of the three different BMI groups, nor between height. Age was significantly different between BMI groups, as was weight, BMI, LBW, and percent body fat. Subject weight ranged from $45-128 \mathrm{~kg}$ and BMI values ranged from $16.9-51.8 \mathrm{~kg} / \mathrm{m}^{2}$.

\section{CT Calibration}

The calibration curve exhibited good linearity across the range of simulated fat contents (Fig. 1). The negative linear correlation was described by a slope and intercept model, where $\mathrm{HU}=-2.02 *$ fat content $(\%)+40.6$ (i.e. fat content $(\%)=(\mathrm{HU}-40.6) /-2.02)(\mathrm{r}$-squared $=0.99, \mathrm{P}<0.001)$. For each of the reference objects used for calibration, the average accuracy of HU readings back-calculated to fat content and expressed as a percentage of actual fat content ranged from $94.8 \%$ to $109 \%$ for intra-day measurements, and $94.1 \%$ to $104 \%$ for inter-day measurements (Table 2). All intra- and inter-day precision values were less than $\pm 12 \%$, and there was no significant difference in precision or accuracy of measurements between days.

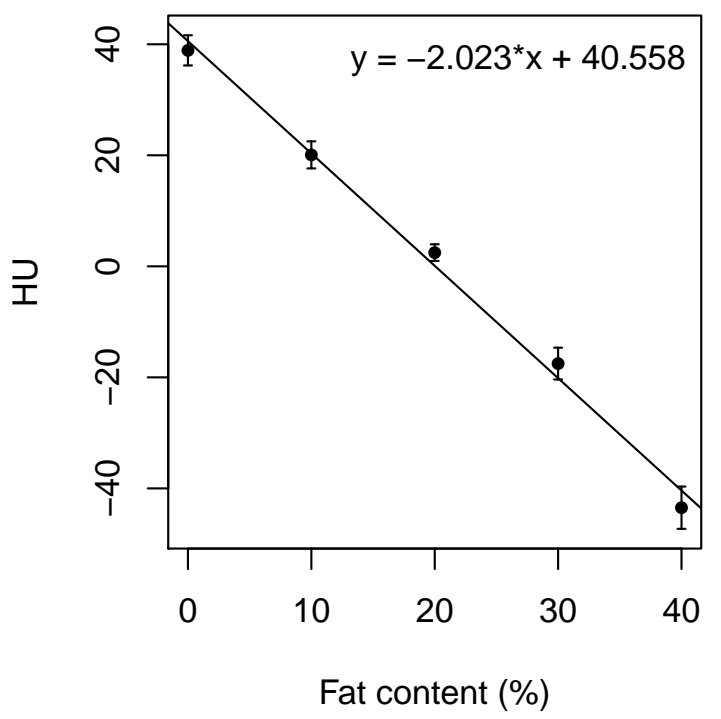

Fig. (1). Negative linear correlation between the CT scan measurement (HU) and fat content (\%) simulated by increasing terbutyl alcohol concentrations $(0,10,20,30 \& 40 \%)$ in glucose $(\mathbf{1 8 . 5 \%} \mathbf{w} / \mathbf{v})$ solution. Data presented as mean \pm standard deviation of measured $\mathrm{HU}$ for each reference object. 
Table 2. Intra- and inter-day accuracy and precision of fat content measurements for the reference objects.

\begin{tabular}{|c|c|c|c|}
\hline \multicolumn{2}{|c|}{ Fat Content (\%) } & \multirow[t]{2}{*}{ Accuracy (\%) } & \multirow[t]{2}{*}{ Precision $(\% \mathrm{CV})$} \\
\hline Actual (Reference) & Measured $($ mean $\pm \mathrm{SD})$ & & \\
\hline \multicolumn{4}{|c|}{ Intra-day } \\
\hline 0 & $0.36 \pm 0.85$ & NA & NA \\
\hline 10 & $9.70 \pm 1.12$ & 97 & 11.5 \\
\hline 20 & $19.0 \pm 0.84$ & 94.8 & 4.46 \\
\hline 30 & $30.0 \pm 0.60$ & 100 & 1.98 \\
\hline 40 & $43.6 \pm 1.27$ & 109 & 2.92 \\
\hline \multicolumn{4}{|c|}{ Inter-day } \\
\hline 0 & $0.82 \pm 1.34$ & NA & NA \\
\hline 10 & $10.1 \pm 1.20$ & 101 & 11.9 \\
\hline 20 & $18.8 \pm 0.74$ & 94.1 & 3.95 \\
\hline 30 & $28.7 \pm 1.42$ & 95.7 & 4.93 \\
\hline 40 & $41.5 \pm 1.88$ & 104 & 4.53 \\
\hline
\end{tabular}
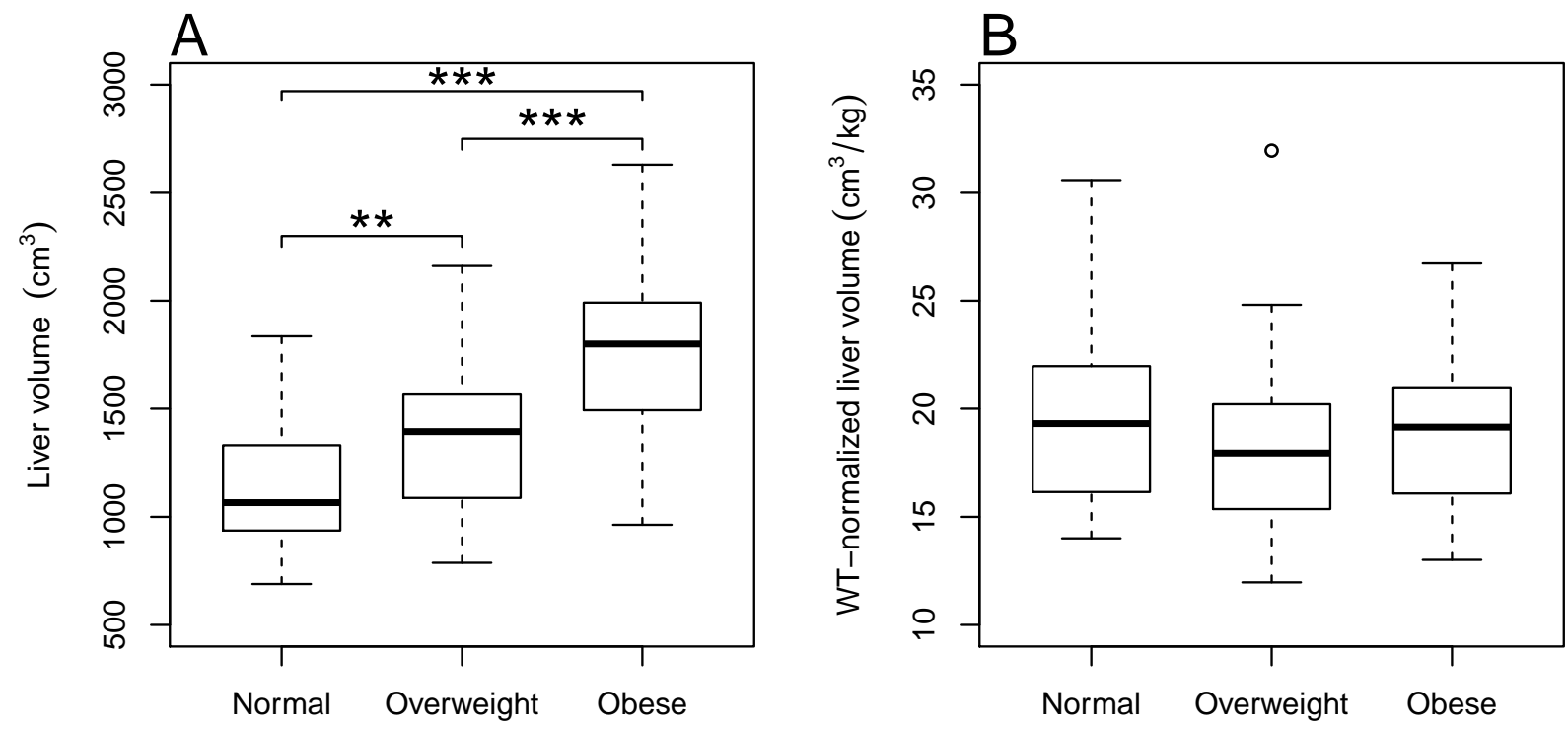

Weight category

Fig. (2). Comparison of liver volume and WT-normalized liver volume between patient BMI categories. Box-plots represent the median (thick line), $25^{\text {th }}-75^{\text {th }}$ percentiles (box), 1.5 times the interquartile range (whiskers) of values, and outliers (points). $* \mathrm{P}$-value $<0.05$, $* * \mathrm{P}$-value $<0.01, * * * \mathrm{P}$-value $<0.001$.

\section{Liver Volume}

Liver volume increased with subject BMI (Fig. 2A \& B, respectively) and was significantly different between BMI categories, with mean \pm SD values of $1138 \pm 277,1374$ \pm 331 , and $1766 \pm 389 \mathrm{~cm}^{3}$ for the normal, overweight, and obese BMI categories, respectively (P-value $<0.001)$. No statistical difference was observed between BMI categories for WT-normalized total liver volume (Fig. (2C), mean \pm SD values $19.5 \pm 3.98,18.5 \pm 4.30$, and $19.0 \pm 3.45 \mathrm{~cm}^{3} / \mathrm{kg}$, respectively).

\section{Liver Fat}

No differences were observed in attenuation readings between the four locations within the liver (mean \pm SD for locations (a) to (d): $33.5 \pm 13.0,32.4 \pm 12.6,32.1 \pm 12.4$, and $31.8 \pm 12.8 \mathrm{HU}$, respectively). Corresponding with a decrease in liver attenuation (Fig. 3A), the percentage of fat in the liver increased with BMI category (Fig. 3B), and was significantly different between BMI categories. Mean \pm SD values (range) of percent liver fat were $-0.654 \pm 4.33(-5.29$ $10.7), 3.02 \pm 4.60(-3.86-16.1)$, and $8.30 \pm 5.80 \%(-3.90-20.0)$ 

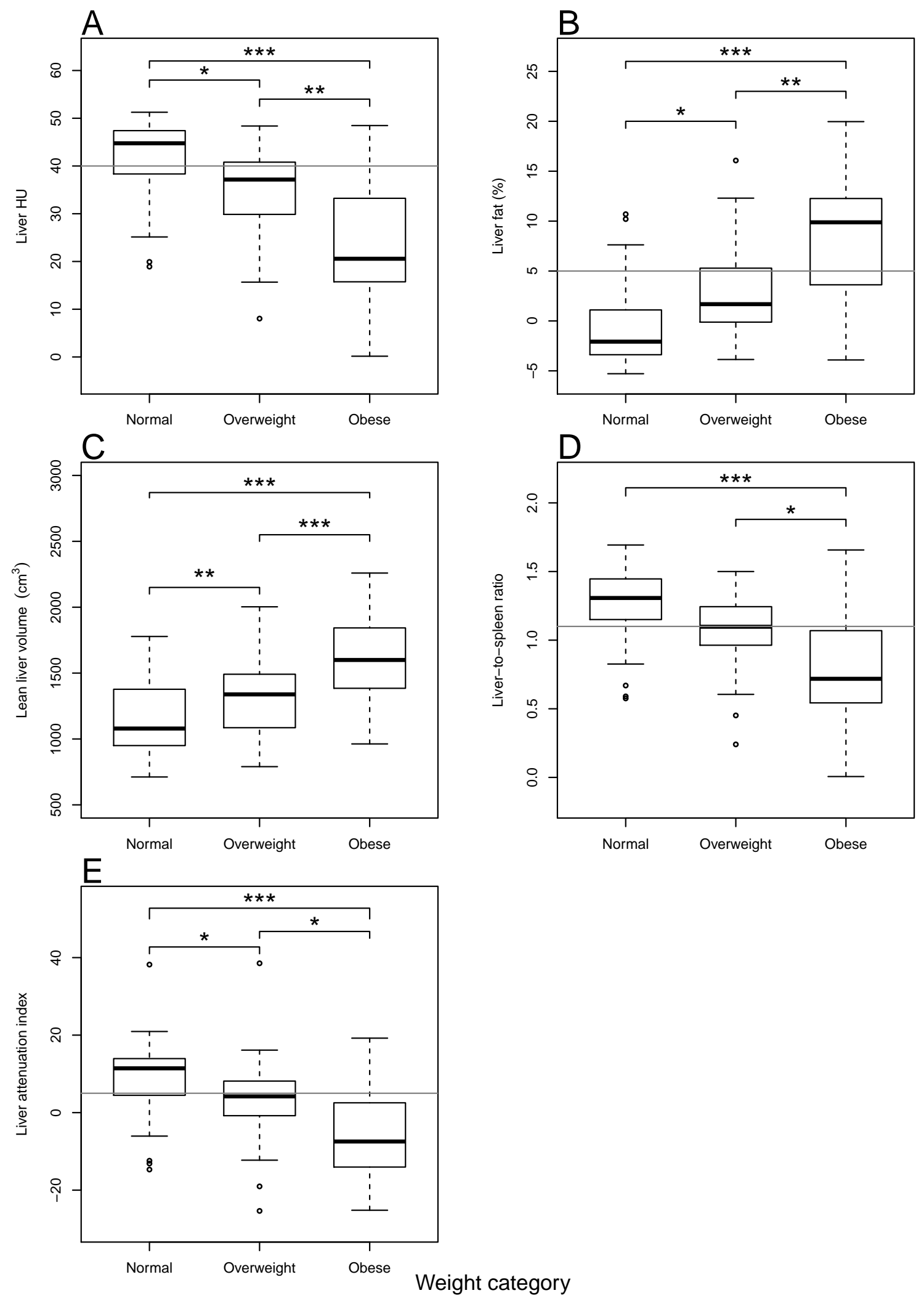

Fig. (3). Comparison of (A) liver attenuation, (B) percent liver fat, (C) lean liver volume, (D) ratio of liver-to-spleen attenuation value, and (E) liver attenuation index (liver HU minus spleen HU) between BMI categories. Horizontal lines represent values used for qualitative diagnosis of fatty liver: liver fat $>5 \%$, liver-to-spleen ratio $\leq 1.1$, and $\mathrm{LAI} \leq 5$. $* \mathrm{P}$-value $<0.05$, **P-value $<0.01$, $* * * \mathrm{P}$-value $<$ 0.001 . 
Table 3. Actual prevalence of mild fatty liver $(\geq 5 \%)$ compared to prevalence determined according to various qualitative diagnostic CT methods for each weight category. Results reported as \% prevalence in each weight category (number of patients).

\begin{tabular}{|c|c|c|c|}
\hline & $\begin{array}{c}\text { Normal } \\
\left(\mathrm{BMI}<25 \mathrm{~kg} / \mathrm{m}^{2}\right)\end{array}$ & $\begin{array}{c}\text { Overweight } \\
(\text { BMI } 25-30 \text { kg/m²) }\end{array}$ & $\begin{array}{c}\text { Obese } \\
\left(\text { BMI } \geq 30 \mathrm{~kg} / \mathrm{m}^{2}\right)\end{array}$ \\
\hline Liver fat $\geq 5 \%$ & $13.3(4)$ & $29.0(9)$ & $66.7(26)$ \\
\hline Liver attenuation $\leq 40 \mathrm{HU}$ & $26.7(8)$ & $64.5(20)$ & $89.7(35)$ \\
\hline Liver-to-spleen ratio $\leq 1.1$ & $20.0(6)$ & $48.4(15)$ & $76.9(30)$ \\
\hline Liver attenuation index $\leq 5$ & $26.7(8)$ & $51.6(16)$ & $84.6(33)$ \\
\hline
\end{tabular}
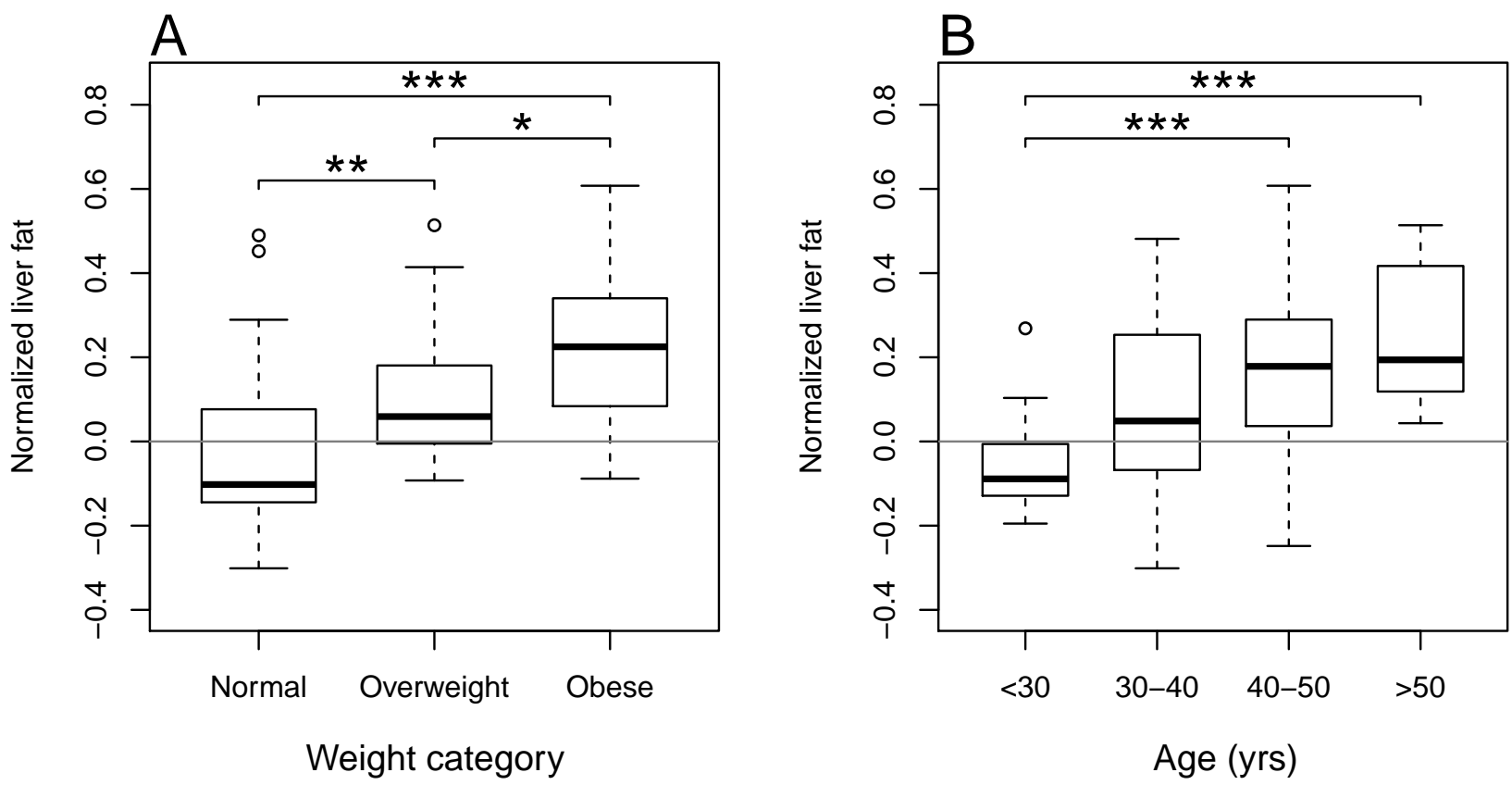

Fig. (4). Liver fat normalized to body fat as a function of (A) BMI category, and (B) age. *P-value $<0.05$, $* * \mathrm{P}-\mathrm{value}<0.01, * * * \mathrm{P}-\mathrm{value}$ $<0.001$.

for the normal, overweight, and obese BMI categories, respectively (P-value $<0.001)$. Lean liver volume also significantly increased with BMI category (Fig. 3C), with mean \pm SD values of $1120 \pm 259,1320 \pm 297$, and $1600 \pm$ $319 \mathrm{~cm}^{3}$.

Splenic attenuation values for three subjects (one from each BMI category) were greater than 5 standard deviations from group means and were therefore deemed to be erroneous measurements. These values were excluded from further analysis. A significant decrease in liver-to-spleen ratio and liver attenuation index was observed across BMI categories (Fig. 3D \& E).

The prevalence of mild fatty liver in this study of 100 subjects increased across BMI categories, with $66.7 \%$ of obese subjects having greater than $5 \%$ liver fat compared to $29.0 \%$ and $13.3 \%$ of overweight and normal subjects, respectively (Table 3). For all BMI categories, the prevalence of fatty liver determined by qualitative diagnostic methods was higher than for measured fat content, with predicted prevalence of fatty liver in obese subjects ranging from $76.9 \%$ for $\mathrm{L} / \mathrm{S} \leq 1.1$ to $89.7 \%$ for $\mathrm{LAI} \leq 40 \mathrm{HU}$.
A significant increase in liver fat normalized by body fat was observed with BMI category (Fig. 4A), with mean values ranging from -0.04 (which can be considered to be zero) in the normal weight category, up to 0.10 in the overweight category, and 0.23 in the obese category (Table 3). A significant increase in liver fat normalized by body fat was also observed with increasing age (Fig. 4B), with mean values ranging from -0.06 in subjects younger than 30 , to 0.26 in subjects older than 50 .

\section{DISCUSSION}

This is the first study to have investigated differences in liver composition across size using a robust design stratified across BMI. Total liver volume was found to significantly increase with BMI, which was not only due to an increase in liver fat, but also an increase in lean liver volume with BMI. This finding is consistent with metabolism increasing with BMI [25], and metabolic clearance of drugs increasing with lean body weight [26]. Furthermore, when normalized to WT, total liver volume was the same across BMI categories. This is consistent with Narawatne et al. [27] who reported that total liver volume correlated with WT. 
Although BMI has been reported to be a good predictor of hepatic steatosis [2], we found that some obese subjects in this study had no or minimal hepatic fat content. Conversely, some normal weight subjects were found to have liver fat content of $\geq 5 \%$, which can be considered to be mild fatty liver [23, 24]. This is consistent with Limanond et al. [20], who reported that BMI correlation with steatosis was marginal, and that normal weight patients may display severe (>30\%) fatty infiltration. Therefore, BMI cannot be considered to be an accurate predictor of fatty liver alone, and other factors, e.g. alcohol intake, triglyceride levels, and liver function $[17,28,29]$, need to be considered when evaluating a patient's risk of steatosis.

Non-contrast enhanced CT of the liver has been widely used as a method for qualitative diagnosis of hepatic steatosis. However, predicted prevalence of steatosis in the population varies according to different methods and cutoff values (e.g. liver HU, L/S, and LAI $[17,19,20])$. We found that the prevalence of mild fatty liver in this study of 100 subjects was overestimated for all BMI categories by every qualitative method considered in this study (liver attenuation $\leq 40 \mathrm{HU}$ [19], $\mathrm{L} / \mathrm{S} \leq 1.1$ [17], and LAI $\leq 5$ [17, 20]), with the worst prediction using the criterion of liver attenuation $\leq 40$ HU. Interestingly, this criterion has been reported to correlate with moderate-to-severe steatosis of $>30 \%$ fatty infiltration [19], whereas L/S $\leq 1.1$ and $\mathrm{LAI} \leq 5$, which were better predictors of steatosis in this study, are associated with milder steatosis (> 5\%) [20]. This finding is consistent with Park et al. [30] who demonstrated that although qualitative methods may display high specificity (i.e. true positive rate) for diagnosis of steatosis, they can lack specificity (i.e. high false positive rate). Furthermore, results demonstrate that use of the spleen as an internal control results in more accurate predictions of the presence of steatosis using qualitative measures. However, quantitative methods are required to best assess the actual extent of fatty infiltration.

In this study, reference objects were used to develop a calibration curve to allow quantitative assessment of liver fat content from liver CT attenuation values. This method has been shown to accurately measure the degree of fatty infiltration when compared to histological assessment [18]. However, previous studies calibrated the CT machine for each subject, which involved concurrent scanning of the reference objects and development of unique equations for each subject by linear regression analysis [16, 18]. We therefore assessed the accuracy and precision of intra- and inter-day measurements of the reference objects to determine the plausibility of less frequent calibration of CT machines for quantification of hepatic fat content. Results showed that the accuracy and precision were similar for intra- and interday measurements of the reference objects, and that there were no significant differences or trends in precision or bias of measurements over time. This finding suggests that calibration for each subject may be unnecessary, adding a significant advantage to the Ricci method [18] in terms of practicality for clinical use. However, the accuracy and precision of inter-day measurements was only determined over a 14 day period, and further investigation will be required to assess the accuracy and precision over a longer time period to determine how often calibration is required. We also note that calibration is still required for each different CT machine, because of interscanner variability in attenuation values [31].

Previous studies have reported an increased mean age of patients diagnosed with fatty liver compared to normal controls [29, 32]. This appeared to correspond however to an increased mean WT [32] or BMI [29] with age. To account for any correlation between weight and BMI with age, in this study, liver fat content was normalized to total body fat and values were compared between age categories. Results showed an increase in normalized liver fat with age, suggesting that the risk factor of fatty infiltration of the liver increases with age, and that the prevalence of hepatic steatosis may be lower in younger obese patients compared to older obese patients. We propose that this may be due to an increased exposure of the liver to fat in the body over time, although longitudinal studies are required to investigate this observation further.

Several limitations to the current study should be acknowledged. Firstly, this study was performed in an Indian population. Although Indians are considered to be Caucasians, findings may differ in other ethnic groups. Secondly, we note that some negative measurements of fat content were calculated using this CT calibration method. This is as a result of natural variability in the underlying hepatic structure of different subjects affecting attenuation readings, e.g. iron, iodine [33], copper, and glycogen content [34], fibrosis or edema [34] may affect attenuation. Therefore, for subjects with little or no hepatic fat content, any variability in attenuation may result in calculation of a negative value using the slope and intercept regression model. For the purpose of this study, all measurements, including negative values, were considered for statistical comparison between BMI or age categories. In clinical practice, however, measurements of fat content below zero using this method can be considered to be zero.

Finally, we note that radiographic attenuation can be non uniform across the liver due to heterogeneity in composition and structure. Nevertheless, CT has been shown to be more sensitive than histological examination for detecting small amounts of fat content in the liver [16], and provides a noninvasive, simple, and reliable method of assessment of hepatic fat content [17]. We also note that no difference in attenuation reading was observed between the four locations in the liver, suggesting that attenuation reading from only one location in the liver may be sufficient for measurement of hepatic fat content in clinical practice.

In conclusion, total liver volume and liver fat increases with BMI. Not all obese subjects, however, were found to have fatty infiltration of the liver. Liver fat normalized to body fat ratio was also found to increase with age, although longitudinal studies are required to determine a mechanism for this observation. We have used a noninvasive, 
non-contrast CT method to assess liver fat content across a range of BMI and age. This method may require less frequent calibration for each machine, although further investigation will be required to assess the long-term accuracy and precision to determine how often calibration is required. This CT method may be suitable for accurate diagnosis and longitudinal evaluation of hepatic steatosis in clinical practice and assessment of donor livers for transplantation.

\section{CONFLICT OF INTEREST}

The authors confirm that this article content has no conflicts of interest.

\section{ACKNOWLEDGEMENTS}

The authors wish to thank the PSG Institute of Medical Sciences and Research Hospitals and PSG \& Sons' Charities Trust for financial assistance, and volunteers for taking part in the study.

\section{ABBREVIATIONS}

\begin{tabular}{|c|c|c|}
\hline BMI & $=$ & body mass index \\
\hline $\mathrm{cm}$ & $=$ & centimeters \\
\hline CT & $=$ & computed tomography \\
\hline $\mathrm{CV}$ & $=$ & coefficient of variation \\
\hline HU & $=$ & Hounsfeld units \\
\hline $\mathrm{L} / \mathrm{S}$ & $=$ & liver-to-spleen ratio \\
\hline LAI & $=$ & liver attenuation index \\
\hline LBW & $=$ & lean body weight \\
\hline MRI & $=$ & magnetic resonance imaging \\
\hline NASH & $=$ & nonalcoholic steatohepatitis \\
\hline NS & $=$ & not significant \\
\hline SD & $=$ & standard deviation \\
\hline WT & $=$ & weight \\
\hline $\mathrm{y}$ & $=$ & years \\
\hline
\end{tabular}

\section{REFERENCES}

[1] Angulo P. Nonalcoholic fatty liver disease. N Engl J Med 2002; 346(16): 1221-31.

[2] Rinella ME, Alonso E, Rao S et al. Body mass index as a predictor of hepatic steatosis in living liver donors. Liver Transpl 2001; 7(5): 409-14.

[3] Bugianesi E, Leone N, Vanni E, et al. Expanding the natural history of nonalcoholic steatohepatitis: from cryptogenic cirrhosis to hepatocellular carcinoma. Gastroenterology 2002; 123(1): $134-40$.

[4] Sanyal AJ, Brunt EM, Kleiner DE, et al. Endpoints and clinical trial design for nonalcoholic steatohepatitis. Hepatology 2011; 54(1): 344-53.

[5] Ploeg RJ, D'Alessandro AM, Knechtle SJ, et al. Risk factors for primary dysfunction after liver transplantation--a multivariate analysis. Transplantation 1993; 55(4): 807-13.

[6] D'Alessandro AM, Kalayoglu M, Sollinger HW, et al. The predictive value of donor liver biopsies for the development of primary nonfunction after orthotopic liver transplantation. Transplantation 1991; 51(1): 157-63.
[7] Chen YS, Cheng YF, De Villa VH, et al. Evaluation of living liver donors. Transplantation 2003; 75(Suppl 3): S16-9.

[8] Urena MA, Moreno Gonzalez E, Romero CJ, Ruiz-Delgado FC, Moreno Sanz C. An approach to the rational use of steatotic donor livers in liver transplantation. Hepatogastroenterology 1999; 46(26): 1164-73.

[9] WHO. Global database on body mass index (BMI). World Health Organization; 2009.

[10] Imber CJ, St Peter SD, Lopez I, Guiver L, Friend PJ. Current practice regarding the use of fatty livers: a trans-Atlantic survey. Liver Transpl 2002; 8(6): 545-9.

[11] Garcia-Tsao G, Boyer JL. Outpatient liver biopsy: how safe is it? Ann Intern Med 1993; 118(2): 150-3.

[12] Friedman LS. Controversies in liver biopsy: who, where, when, how, why? Curr Gastroenterol Rep 2004; 6(1): 30-6.

[13] Dam-Larsen S, Franzmann M, Andersen IB, et al. Long term prognosis of fatty liver: risk of chronic liver disease and death. Gut 2004; 53(5): 750-5.

[14] Longo R, Ricci C, Masutti F, et al. Fatty infiltration of the liver. Quantification by $1 \mathrm{H}$ localized magnetic resonance spectroscopy and comparison with computed tomography. Invest Radiol 1993; 28(4): 297-302.

[15] Qayyum A, Chen DM, Breiman RS, et al. Evaluation of diffuse liver steatosis by ultrasound, computed tomography, and magnetic resonance imaging: which modality is best? Clin Imaging 2009; 33(2): 110-5.

[16] Cheng YF, Chen CL, Lai CY, et al. Assessment of donor fatty livers for liver transplantation. Transplantation 2001; 71(9): 1221-5.

[17] Boyce CJ, Pickhardt PJ, Kim DH, et al. Hepatic steatosis (fatty liver disease) in asymptomatic adults identified by unenhanced low-dose CT. Am J Roentgenol 2010; 194(3): 623-8.

[18] Ricci C, Longo R, Gioulis E, et al. Noninvasive in vivo quantitative assessment of fat content in human liver. J Hepatol 1997; 27(1): 108-13.

[19] Kodama Y, Ng CS, Wu TT, Ayers GD, et al. Comparison of CT methods for determining the fat content of the liver. Am J Roentgenol 2007; 188(5): 1307-12.

[20] Limanond P, Raman SS, Lassman C, et al. Macrovesicular hepatic steatosis in living related liver donors: correlation between CT and histologic findings. Radiology 2004; 230(1): 276-80.

[21] Cohen J. Statistical power analysis for the behavioural sciences. $2^{\text {nd }}$ ed. New Jersey: Lawrence Erlbaum Associates; 1988

[22] Janmahasatian S, Duffull SB, Ash S, Ward LC, Byrne NM, Green B. Quantification of lean bodyweight. Clin Pharmacokinet 2005; 44(10): 1051-65.

[23] Sherlock S, Dooley J. Nutritional and metabolic liver diseases. In: Sherlock S, Dooley J, eds. Diseases of the liver and biliary system. $9^{\text {th }}$ ed. Oxford: Blackwell Scientific Publications; 1993. p. 408-13.

[24] Kleiner DE, Brunt EM, Van Natta M, et al. Design and validation of a histological scoring system for nonalcoholic fatty liver disease. Hepatology 2005; 41(6): 1313-21.

[25] White CR, Seymour RS. Mammalian basal metabolic rate is proportional to body mass 2/3. Proc Natl Acad Sci USA 2003; 100(7): 4046-9.

[26] McLeay SC, Morrish GA, Kirkpatrick CM, Green B. The relationship between drug clearance and body size: systematic review and meta-analysis of the literature published from 2000 to 2007. Clin Pharmacokinet 2012; 51(5): 319-30.

[27] Nawaratne S, Brien JE, Seeman E, et al. Relationships among liver and kidney volumes, lean body mass and drug clearance. Br J Clin Pharmacol 1998; 46(5): 447-52.

[28] Lee JH, Kim D, Kim HJ, et al. Hepatic steatosis index: a simple screening tool reflecting nonalcoholic fatty liver disease. Dig Liver Dis 2010; 42(7): 503-8.

[29] Park YJ, Lim JH, Kwon ER, et al. Development and validation of a simple index system to predict nonalcoholic fatty liver disease. Korean J Hepatol 2011; 17(1): 19-26.

[30] Park SH, Kim PN, Kim KW, et al. Macrovesicular hepatic steatosis in living liver donors: use of CT for quantitative and qualitative assessment. Radiology 2006; 239(1): 105-12.

[31] Birnbaum BA, Hindman N, Lee J, Babb JS. Multi-detector row CT attenuation measurements: assessment of intra- and inter- scanner variability with an anthropomorphic body CT phantom. Radiology 2007; 242(1): 109-19. 
[32] Adam R, Reynes M, Johann M, et al. The outcome of steatotic grafts in liver transplantation. Transplant Proc 1991; 23(1 Pt 2): 1538-40.

[33] Fischer MA, Gnannt R, Raptis D, et al. Quantification of liver fat in the presence of iron and iodine: an ex-vivo dual-energy CT study. Invest Radiol 2011; 46(6): 351-8.
[34] Johnston RJ, Stamm ER, Lewin JM, Hendrick RE, Archer PG. Diagnosis of fatty infiltration of the liver on contrast enhanced CT: limitations of liver-minus-spleen attenuation difference measurements. Abdom Imaging 1998; 23(4): 409-15.

Received: July 23, 2013

Revised: January 21, 2014

Accepted: February 24, 2014

(C) McLeay et al.; Licensee Bentham Open.

This is an open access article licensed under the terms of the Creative Commons Attribution Non-Commercial License (http://creativecommons.org/licenses/by-nc/3.0/) which permits unrestricted, non-commercial use, distribution and reproduction in any medium, provided the work is properly cited. 